\title{
Determinação da energia metabolizável e balanço de nitrogênio de dietas com diferentes teores de proteína bruta para frangos de corte
}

\author{
[Nitrogen balance and metabolizable energy determination of diets with different crude protein \\ levels for broiler chickens] \\ C.H.F. Vasconcellos ${ }^{1}$, D.O. Fontes ${ }^{2}$, L.J.C. Lara $^{2}$, T.Z.B. Vidal ${ }^{3}$, M.A. Silva ${ }^{2}$, P.C. Silva ${ }^{4}$ \\ ${ }^{1}$ Aluno de pós-graduação - EV-UFMG - Belo Horizonte, MG \\ ${ }^{2}$ Escola de Veterinária - UFMG \\ Caixa Postal 567 \\ 30123-970 - Belo Horizonte, MG \\ ${ }^{3}$ Aluna de pós-graduação - EV-UFMG - Belo Horizonte, MG \\ ${ }^{4}$ Aluna de graduação - EV-UFMG - Belo Horizonte, MG
}

\begin{abstract}
RESUMO
Realizou-se um ensaio de metabolismo para avaliar os efeitos de diferentes níveis de proteína bruta (PB) sobre a digestibilidade de nutrientes e energia de dietas para frangos de corte. Foram utilizados 160 frangos de corte de linhagem comercial, distribuídos em delineamento inteiramente ao acaso, com quatro tratamentos - teor de PB - e quatro repetições com 10 aves por unidade experimental. As aves foram alojadas em gaiolas metálicas. A coleta de excretas foi feita nas aves dos 25 aos 29 dias de idade. Os teores de PB utilizados foram 21, 19, 17 e 15\%. A redução do teor de PB melhorou linearmente a digestibilidade da MS e da energia metabolizável (EB). A digestibilidade da PB foi influenciada quadraticamente pelos níveis de PB da dieta, sendo o nível de 15,3\% de PB o que proporcionou melhor digestibilidade da PB. Houve diminuição linear do consumo e excreção de nitrogênio com a redução proteica. O nitrogênio retido e a eficiência de utilização do nitrogênio apresentaram melhor resultado nos teores de 18,3 e 15,3\%, respectivamente. Não houve efeito do teor de PB sobre a energia metabolizável aparente e sobre a energia metabolizável aparente corrigida para balanço de nitrogênio.
\end{abstract}

Palavras-chave: digestibilidade, proteína, energia, nitrogênio, frango de corte

\begin{abstract}
A metabolism trial was carried out in metabolic cages in a completely randomized experimental design to evaluate the effect of $C P$ reduction on nutrients and energy digestibility in the diets of broiler chickens. A hundred sixty male broiler chickens were randomly allotted to four treatments (CP levels) and four replicates of 10 birds each. The crude protein levels used in the diets were 21, 19, 17 and 15. The total excreta was colleted and recorded from 25 to 29 days of age. The CP reduction improved dry matter and energy digestibility linearly. A quadratic effect of the CP level on CP digestibility was observed. The maximum digestibility was estimated for broilers fed $15.3 \%$ CP diets. The nitrogen intake and excretion decreased linearly with the CP reduction. The maximum retained nitrogen and nitrogen efficiency utilization were estimated for broilers fed 18.3 and $15.3 \%$ CP diets, respectively. No effect of CP levels on ME was observed.
\end{abstract}

Keywords: digestibility, protein, energy, nitrogen, broiler chicken

Recebido em 28 de setembro de 2009

Aceito em 13 de abril de 2011

E-mail: carloshzoo@yahoo.com.br 


\section{INTRODUÇÃO}

A alimentação representa cerca de $70 \%$ do custo de produção de aves, sendo a energia a responsável pela maior parte desse custo. A correta avaliação do valor energético dos alimentos e das dietas, bem como adequada utilização dos nutrientes, é extremamente importante tanto para formulação de mínimo custo quanto para atendimento às exigências nutricionais das aves. No caso das aves, estimase que somente 35 a $45 \%$ do nitrogênio proteico consumido são transformados em produto animal.

De acordo com Noblet et al. (1987) e Roth et al. (1999), dietas com baixo teor de proteína têm sido associadas com redução de perdas energéticas. Deve-se levar em consideração que o aumento do suprimento de proteína está diretamente associado com um maior turnover proteico (Reeds et al., 1981; Roth et al., 1999; van Milgen et al., 2001) e que o aumento do peso das vísceras (Noblet et al., 1987) se relaciona com o subsequente aumento da produção de calor. Com isso, a utilização de dietas de baixa proteína leva à diminuição da desaminação e produção de calor pelos animais devido aos excessos de proteína, além da menor produção e excreção de nitrogênio pela urina. Essas dietas, segundo esses autores, podem melhorar a disponibilidade energética para deposição de tecidos.

Dietas com baixo teor de proteína têm sido associadas à redução de perdas energéticas. Ao se diminuírem os teores de proteína bruta da dieta, reduzem-se, também, a desaminação do excesso de aminoácidos e, com isso, a síntese e a excreção de ácido úrico nas excretas das aves. Além disso, ocorrem menor taxa de turnover das proteínas corporais e diminuição da produção de calor dos animais. Consequentemente, a redução do teor de proteína bruta da dieta aumenta a disponibilidade de energia para a deposição de tecidos.

Rostagno et al. (2002) observaram que a redução do conteúdo proteico em $2 \%$ resultou em consumo de proteína $8 \%$ menor; além disso, as dietas com menor teor proteico resultaram em camas com menor umidade. Em experimento semelhante, Ferguson et al. (1998) verificaram redução na concentração de $\mathrm{NH}_{3}$ no ar, da umidade da cama e da excreção de $\mathrm{N}$ com teores baixos de proteína na ração. Da mesma forma, Gates (2000) encontrou menor concentração de amônia $\left(\mathrm{NH}_{3}\right)$ na cama de frangos alimentados com dietas com teor reduzido de proteína bruta (PB) e suplementadas com aminoácidos essenciais.

Ainda, em relação à excreção nitrogenada, Faria Filho et al. (2005) observaram redução gradual da excreção de nitrogênio à medida que se reduzia o teor de proteína da dieta. Aletor et al. (2000) relataram maior eficiência de utilização da proteína e redução de $41 \%$ na eliminação de nitrogênio de uma dieta de 22,5\% de PB para outra que continha 15,3\%. Resultados semelhantes foram encontrados por Faria Filho et al. (2006), Corzo et al. (2005) e Blair et al. (1999). Silva et al. (2006) também verificaram menor excreção de nitrogênio e maior eficiência de retenção quando trabalharam com dietas de reduzido teor proteico, suplementadas com fitase.

Sabe-se que a composição e a quantidade de excretas produzidas por um animal estão diretamente relacionadas à concentração e à composição de nutrientes do alimento fornecido. Dessa forma, o nutricionista tem papel fundamental não apenas na melhoria da produção e do desempenho animal, mas também na redução do poder poluente dos dejetos. Assim, para reduzir perdas e o consequente comprometimento do meio ambiente, o conhecimento de alguns procedimentos em nutrição animal é importante.

A redução proteica permite diminuir a perda de nitrogênio na ordem de 30 a 40\%. A indústria de produção de proteína animal tem se mostrado altamente competitiva, e pequenas diferenças na eficiência de utilização dos alimentos podem ter grandes impactos econômicos. Dessa forma, o objetivo deste experimento foi determinar a energia metabolizável e o balanço de nitrogênio de dietas com diferentes teores de proteína bruta.

\section{MATERIAL E MÉTODOS}

Foram utilizados 160 pintos de corte, machos, de linhagem comercial, distribuídos em delineamento inteiramente ao acaso, em quatro tratamentos com 10 aves por repetição cada. Os animais foram alojados e criados até os 29 dias 
de idade em gaiolas metabólicas metálicas providas de bebedouros, comedouros e coletores de excretas. Até 14 dias, as aves foram aquecidas utilizando-se lâmpadas comuns de 100 watts. Os pintos foram vacinados no incubatório contra a doença de Marek. Posteriormente, as aves foram pesadas e distribuídas de maneira uniforme entre os tratamentos. No período entre 21 e 25 dias de idade, as aves foram adaptadas às dietas e às condições experimentais.

As aves foram criadas até os 21 dias de idade e alimentadas com dieta formulada para atender às exigências preconizadas por Rostagno et al. (2005). A partir do $21^{\circ}$ dia, foram alimentadas com quatro dietas que continham diferentes níveis de proteína bruta para se determinar o efeito do teor de proteína sobre a digestibilidade da matéria seca e da proteína bruta, e sobre a energia metabolizável e o balanço de nitrogênio. O percentual de proteína bruta das dietas experimentais foi de 21 - dieta-controle -, 19, 17 e 15\%, (Tab. 1). As dietas com teor proteico mais baixo foram suplementadas com aminoácidos sintéticos - L-lisina; DL- metionina; L-treonina; L-triptofano; L-isoleucina, L-valina e L-arginina - para manter constante a relação lisina digestível e os demais aminoácidos essenciais, de acordo com Rostagno et al. (2005). Foram suplementadas com casca de soja para manter constante o teor de fibra bruta, e fornecidas à vontade durante todo o período experimental, determinando-se, durante o período de coleta de excretas, o consumo por meio da pesagem diária da ração fornecida e das sobras.

As determinações da digestibilidade dos nutrientes e da energia metabolizável aparente e energia metabolizável aparente corrigida para balanço de nitrogênio das dietas foram realizadas por meio do método tradicional de coleta total de excretas. O período de coleta ocorreu do $25^{\circ}$ ao $29^{\circ}$ dia de idade. As quantidades oferecidas e as sobras foram pesadas diariamente e as excretas coletadas duas vezes ao dia durante o período de cinco dias de coleta. O material recolhido foi colocado em sacos plásticos, pesado e armazenado em congelador, até o período final da coleta. Posteriormente, as excretas foram pesadas e colocadas em estufa de ventilação forçada a $65^{\circ} \mathrm{C}$, durante 48 horas, para présecagem. Após a pré-secagem, o material foi exposto, por duas horas, à temperatura ambiente e, em seguida, pesado e homogeneizado para a coleta de amostras e determinação de matéria seca, energia bruta e nitrogênio.

As dietas experimentais foram também analisadas para o conteúdo de matéria seca, energia bruta e nitrogênio conforme técnicas descritas por AOAC (Official..., 1995). Os teores de energia bruta foram determinados em bomba calorimétrica adiabática. A partir dos dados de consumo de dieta, de produção de excretas e dos resultados das análises de laboratório, procedeuse ao cálculo dos coeficientes de digestibilidade da proteína bruta (PB), da matéria seca (MS) e da energia bruta (EB). A partir do consumo de matéria seca, da determinação dos valores de energia bruta e do nitrogênio das dietas e das excretas, calcularam-se a energia metabolizável aparente (EMA) e a energia metabolizável aparente corrida para balanço de nitrogênio (EMAn).

O balanço de nitrogênio entre as diferentes dietas nas diferentes fases foi calculado por intermédio da diferença entre nitrogênio ingerido e a perda de nitrogênio nas excretas. Dessa forma, obtevese, também, o nitrogênio retido.

Os valores de proteína bruta consumida (PBC) e de proteína bruta das excretas (PBE) foram obtidos pela multiplicação dos teores de proteína pelas quantidades de dieta consumida e excretas coletadas, respectivamente. A partir destes, foram calculadas a $\mathrm{PB}$ retida $(\mathrm{PBR}=\mathrm{PBC}-$ PBE) e a eficiência de utilização do nitrogênio $(E U N=N R / N C)$, em que NR é o nitrogênio retido, e NC o nitrogênio consumido.

Para avaliação da digestibilidade dos nutrientes, foi utilizado o delineamento experimental inteiramente ao acaso, com quatro tratamentos (dietas) e quatro repetições, com 10 aves por unidade experimental. As análises dos dados foram feitas por meio do programa SAEG (Sistema... 2007). O efeito do teor de proteína bruta foi calculado por análise de regressão, desdobrando-se os graus de liberdade em seus componentes lineares e quadráticos para a escolha do modelo de regressão que melhor descrevesse as observações. 
Tabela 1. Composição percentual e valores nutricionais calculados das dietas com teores reduzidos de proteína bruta na fase de crescimento

\begin{tabular}{|c|c|c|c|c|}
\hline \multirow{2}{*}{ Ingredientes } & \multicolumn{4}{|c|}{ Tratamento/teor de PB } \\
\hline & T1 & $\mathrm{T} 2$ & T3 & $\mathrm{T} 4$ \\
\hline Milho & 55,97 & 55,97 & 55,97 & 55,97 \\
\hline Farelo de soja & 35,85 & 30,65 & 25,37 & 20,02 \\
\hline Óleo de soja & 4,65 & 4,65 & 4,65 & 4,65 \\
\hline Amido & - & 2,74 & 5,48 & 8,21 \\
\hline Casca de soja & - & 0,83 & 1,69 & 2,57 \\
\hline Calcário & 0,84 & 0,83 & 0,82 & 0,81 \\
\hline Fosfato bic. & 1,68 & 1,73 & 1,78 & 1,83 \\
\hline Sal comum & 0,41 & 0,41 & 0,41 & 0,41 \\
\hline Inerte & - & 1,32 & 2,39 & 3,22 \\
\hline Premix vit. mineral ${ }^{1}$ & 0,4 & 0,4 & 0,4 & 0,4 \\
\hline DL-Metionina & 0,181 & 0,24 & 0,30 & 0,35 \\
\hline L-lisina & 0,024 & 0,19 & 0,36 & 0,53 \\
\hline L-treonina & - & 0,047 & 0,13 & 0,22 \\
\hline L-arginina & - & - & 0,08 & 0,26 \\
\hline L-isoleucina & - & - & 0,06 & 0,16 \\
\hline L-valina & - & - & 0,1 & 0,20 \\
\hline L-fenilalanina & - & - & - & 0,13 \\
\hline L- histidina & - & - & - & 0,019 \\
\hline L-triptofano & - & - & 0,003 & 0,034 \\
\hline \multicolumn{5}{|l|}{ Níveis Nutricionais } \\
\hline Proteína bruta (\%) & 21 & 19 & 17 & 15 \\
\hline EMA (kcal/kg) & 3,120 & 3,120 & 3,120 & 3,120 \\
\hline Cálcio (\%) & 0,84 & 0,84 & 0,84 & 0,84 \\
\hline Fósforo disp. (\%) & 0,42 & 0,42 & 0,42 & 0,42 \\
\hline Fibra bruta (\%) & 2,91 & 2,91 & 2,91 & 2,91 \\
\hline Lisina dig. (\%) & 1,05 & 1,05 & 1,05 & 1,05 \\
\hline Met. + cis. dig. (\%) & 0,76 & 0,76 & 0,76 & 0,76 \\
\hline Treonina dig. (\%) & 0,71 & 0,68 & 0,68 & 0,68 \\
\hline Triptofano dig. (\%) & 0,23 & 0,21 & 0,18 & 0,18 \\
\hline Isoleucina dig. (\%) & 0,83 & 0,74 & 0,70 & 0,70 \\
\hline Valina dig. (\%) & 0,89 & 0,79 & 0,79 & 0,79 \\
\hline Arginina dig. (\%) & 1,35 & 1,19 & 1,10 & 1,10 \\
\hline Fenil.+ tir. dig. (\%) & 1,64 & 1,46 & 1,27 & 1,21 \\
\hline Gli + Ser. total (\%) & 1,92 & 1,71 & 1,51 & 1,30 \\
\hline
\end{tabular}

${ }^{1}$ Suplemento Vitamínico-mineral - composição por kg: vit A(UI) 2.000.000; vit D3(UI)375.000; vit E (mg) 3.750; vit B1(mg) 250; vit B2 (mg) 750; vit B6 (mg) 500; vit B12 (mcg) 3750; niacina (mg) 6250; ac. pantotênico (mg) 2500; biotina (mg) 10; ac. fólico (mg) 125mg; colina (mg) 75000; selênio (mg) 45; iodo (mg) 175; ferro (mg) 12525; cobre (mg) 2.500; manganês (mg) 19.500; zinco (mg) 13.750; avilamicina (mg) 15.000; narasin (mg) 12.250; BHT (mg) 500. ENA: energia metabolizável aparente.

\section{RESULTADOS E DISCUSSÃO}

Os dados de digestibilidade dos nutrientes das dietas experimentais encontram-se na Tab. 2. Houve efeito linear do teor de proteína bruta sobre a digestibilidade da MS e da EB, de acordo com as seguintes equações de regressão: $\hat{Y}=80,9580-0,563194 X$ (Fig. 1) e $\hat{Y}=87,2870$ -
0,679175X (Fig. 2). Assim, o teor de 15\% de PB foi o que permitiu melhor digestibilidade da MS e da EB. O coeficiente de digestibilidade da PB apresentou efeito quadrático segundo a equação $\hat{\mathrm{Y}}=-37,9177+13,7686 \mathrm{X}-0,448983 \mathrm{X}^{2}$, sendo estimado o teor de $15,3 \%$ o de maior coeficiente de digestibilidade da PB (Fig. 3). 
Determinação da energia metabolizável...

Tabela 2. Coeficientes de digestibilidade (\%) da matéria seca (CDMS), da proteína bruta (CDPB) e da energia bruta (CDEB) das dietas de acordo com o teor de proteína bruta da dieta

\begin{tabular}{cccc}
\hline $\begin{array}{c}\text { Teor de proteína } \\
\text { bruta (\%) }\end{array}$ & CDMS & CDPB & CDEB \\
\hline 21 & 69,43 & 53,03 & 73,07 \\
19 & 69,79 & 62,17 & 74,43 \\
17 & 71,44 & 65,83 & 75,52 \\
15 & 72,63 & 67,78 & 77,23 \\
\hline CV (\%) & 1,68 & 4,03 & 1,47 \\
\hline Significância & $*$ & $*$ & $*$ \\
\hline
\end{tabular}

Equação de regressão

\begin{tabular}{ll}
\hline CDMS & ${ }^{1}$ Efeito linear $(\mathrm{P}<0,01), \hat{\mathrm{Y}}=80,9580-0,563194 \mathrm{X}\left(\mathrm{R}^{2}=0,95\right)$ \\
CDPB & ${ }^{2}$ Efeito quadrático $(\mathrm{P}<0,05), \hat{\mathrm{Y}}=-37,9177+13,7686 \mathrm{X}-0,448983 \mathrm{X}^{2}\left(\mathrm{R}^{2}=0,99\right)$ \\
CDEB & ${ }^{3}$ Efeito linear $(\mathrm{P}<0,01), \hat{\mathrm{Y}}=87,2870-0,679175 \mathrm{X}\left(\mathrm{R}^{2}=0,99\right)$
\end{tabular}

\begin{abstract}
* Significativo $(\mathrm{P}<0,05)$.
Houve melhora no aproveitamento da MS e da EB quando se reduziu o teor de PB da dieta. Estes dados mostram que a redução do teor proteico das dietas torna as dietas mais eficientes do ponto de vista energético. Existe, ainda, menor desperdício de nutrientes com a melhora da digestibilidade da PB e MS. Resultados mais favoráveis na digestibilidade da MS com redução do teor de $\mathrm{PB}$ na dieta de frangos de corte também foram encontrados por Rocha et al. (2003). Faria Filho et al. (2005) e Faria Filho et al. (2006), ao trabalharem com esse tipo de dieta, observaram melhora na digestibilidade do nitrogênio à medida que o teor de $\mathrm{PB}$ foi reduzido.
\end{abstract}

Blair et al. (1999), Aletor et al. (2000) e Corzo et al. (2005) observaram que frangos de corte alimentados com dietas com baixa PB apresentaram melhor eficiência de retenção e menor excreção de nitrogênio (melhor digestibilidade da PB). Da mesma forma, Namroud et al. (2008) verificaram diminuição na excreção nitrogenada com a redução do teor de PB da dieta. Baretta Netto (2003) também observou melhora na digestibilidade da MS, maior retenção de $\mathrm{PB}$ e maior EMAn com a redução proteica na dieta para frangos na fase de crescimento, ao trabalhar com redução de proteína para frangos.

De acordo com Rodrigues et al. (2007), a digestibilidade da matéria seca para frangos e poedeiras varia de 70 a $75 \%$, o que sugere uma lacuna para atuação dos nutricionistas que visam melhorar este valor e, consequentemente, reduzir a excreção de elementos potencialmente poluentes. De acordo com os resultados obtidos no presente trabalho, as dietas de baixa $\mathrm{PB}$ permitiram melhor digestibilidade da MS e consequente redução da excreção de nitrogênio. Redução na excreção nitrogenada com redução de PB da ração também foi constatada por Kerr e Kidd (1999). Silva (2004) observou que aves alimentadas com dietas com teor reduzido de PB e suplementadas com fitase diminuíram o consumo e a excreção de nitrogênio em relação àquelas alimentadas com dieta-controle; além disso, o autor observou aumento no coeficiente de digestibilidade da MS e no conteúdo de EMAn. O aumento do conteúdo de EMAn, de acordo com o autor, pode estar associado à utilização de maior quantidade de aminoácidos industriais que não tiveram seu valor energético incluído no cálculo das dietas. 
Vasconcellos et al.

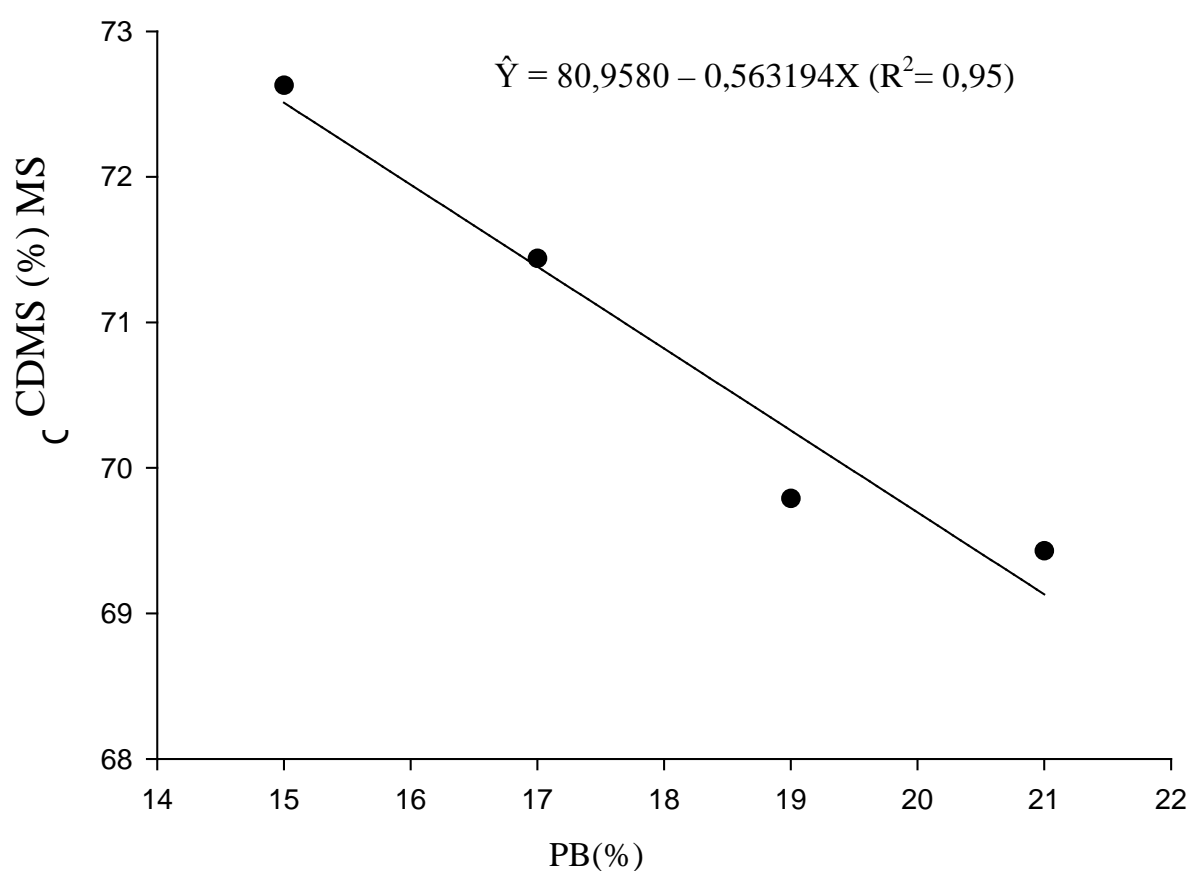

Figura 1. Regressão do coeficiente de digestibilidade da matéria seca (CDMS) de dietas em relação ao teor de proteína bruta $(\mathrm{PB})$ da dieta para frangos de corte.

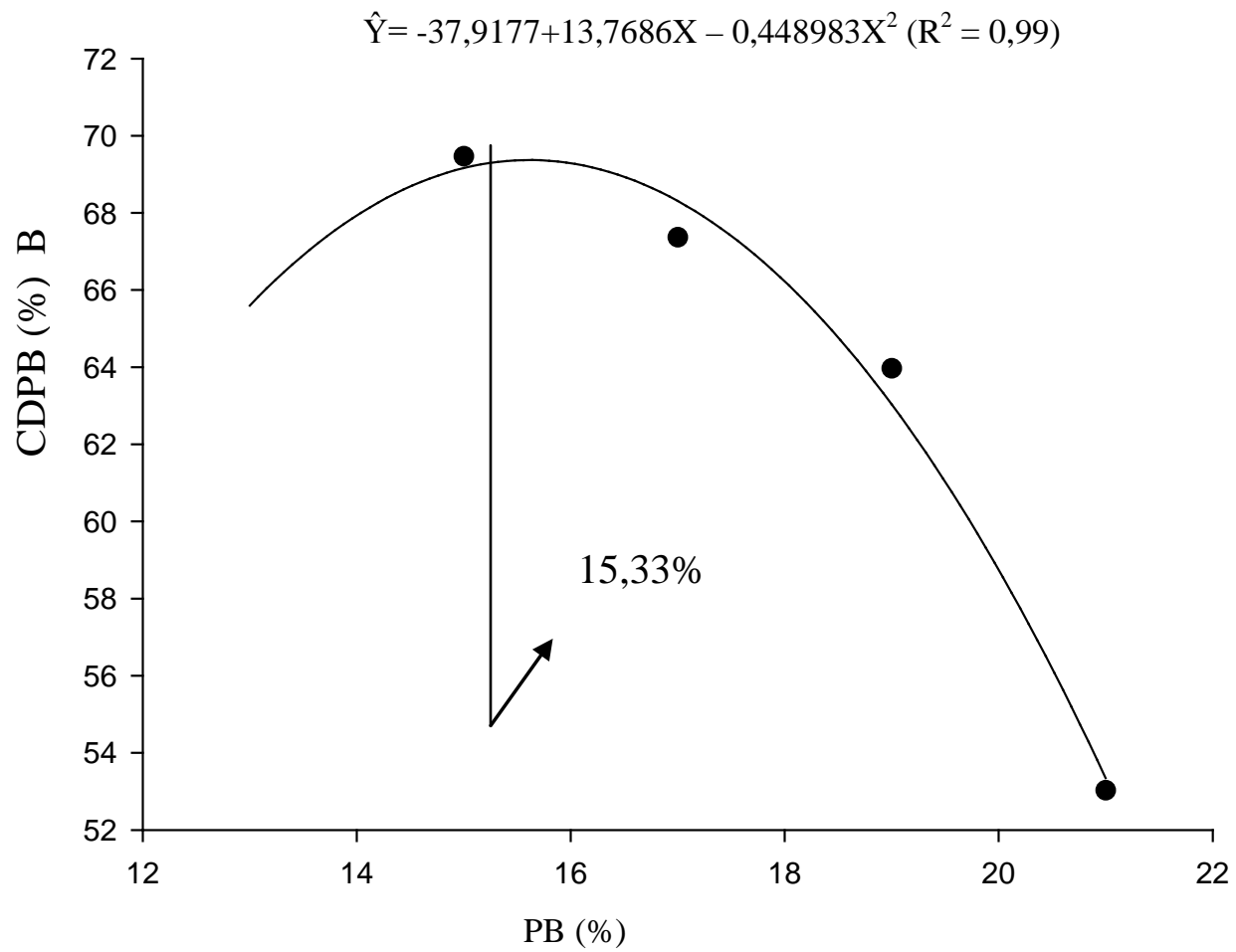

Figura 2. Regressão do coeficiente de digestibilidade da proteína bruta (CDPB) de dietas em relação ao teor de proteína bruta (PB) da dieta para frangos de corte. 


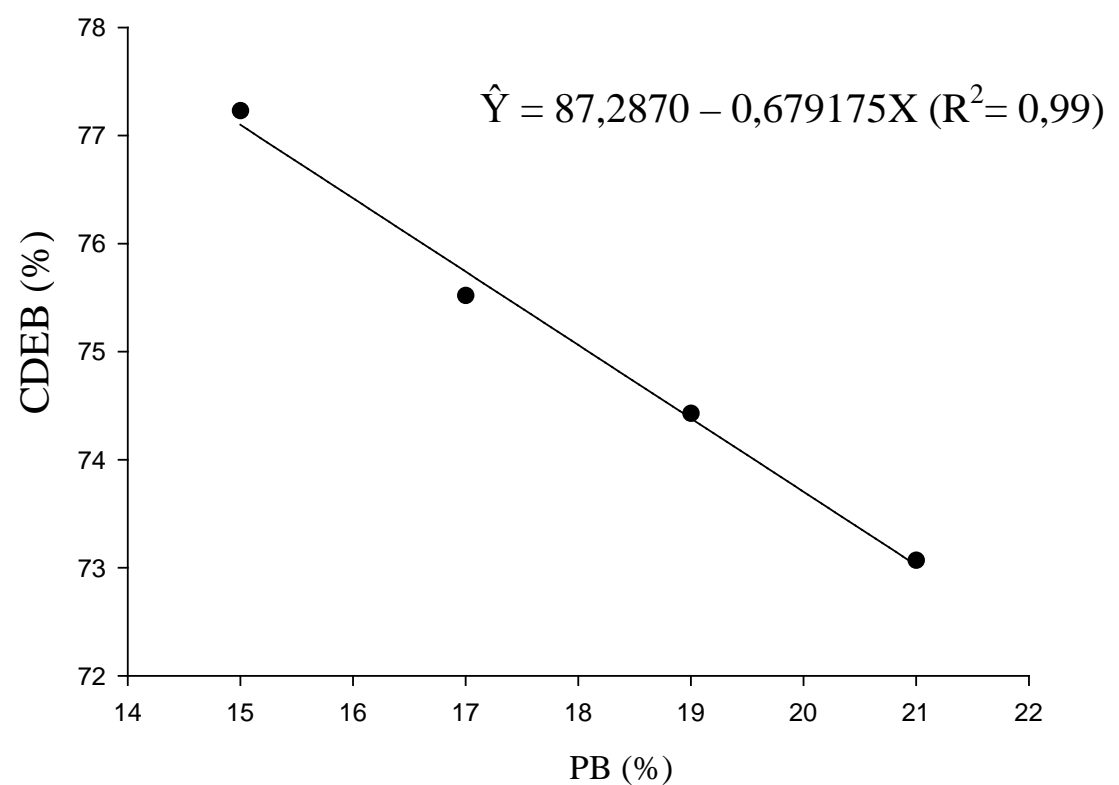

Figura 3. Regressão do coeficiente de digestibilidade da energia bruta (CDEB) de dietas em relação ao teor de proteína bruta (PB) da dieta para frangos de corte.

Os dados de nitrogênio ingerido (g), nitrogênio excretado (g) e nitrogênio retido (g) são apresentados na Tab. 3. Estes resultados representam o consumo, a excreção e a retenção de nitrogênio de um grupo de 10 aves alimentadas com dietas que continham diferentes teores de proteína bruta.

Tabela 3. Valor do balanço de nitrogênio de frangos de corte em crescimento, de acordo com o teor de proteína bruta da dieta

\begin{tabular}{|c|c|c|c|c|}
\hline $\begin{array}{l}\text { Teor de proteína } \\
\text { bruta (\%) }\end{array}$ & $\begin{array}{c}\text { Nitrogênio } \\
\text { ingerido (g/dia) }\end{array}$ & $\begin{array}{l}\text { Nitrogênio } \\
\text { excretado } \\
\text { (g/dia) }\end{array}$ & $\begin{array}{l}\text { Nitrogênio retido } \\
\text { (g/dia) }{ }^{*}\end{array}$ & $\begin{array}{c}\text { Eficiência de utilização do } \\
\text { nitrogênio } \\
(\%)^{*}\end{array}$ \\
\hline 21 & 42,69 & 20,6 & 22,63 & 53,03 \\
\hline 19 & 40,15 & 15,18 & 24,97 & 62,17 \\
\hline 17 & 36,56 & 12,47 & 24,09 & 65,83 \\
\hline 15 & 32,22 & 10,38 & 21,84 & 67,78 \\
\hline $\mathrm{CV}$ & 2,71 & 6,19 & 5,84 & 4,03 \\
\hline Significância & $*$ & * & $*$ & * \\
\hline $\begin{array}{l}\text { Nitrogênio } \\
\text { ingerido }\end{array}$ & \multicolumn{4}{|c|}{ Efeito linear $(\mathrm{P}<0,01) \hat{\mathrm{Y}}=6,39079+1,75084 \mathrm{X}\left(\mathrm{R}^{2}=0,99\right)$} \\
\hline $\begin{array}{l}\text { Nitrogênio } \\
\text { excretado }\end{array}$ & \multicolumn{4}{|c|}{ Efeito linear $(\mathrm{P}<0,01) \hat{\mathrm{Y}}=-14,0568+1,58766 \mathrm{X}\left(\mathrm{R}^{2}=0,96\right)$} \\
\hline $\begin{array}{l}\text { Nitrogênio } \\
\text { retido }\end{array}$ & \multicolumn{4}{|c|}{ Efeito quadrático $(\mathrm{P}<0,01) \hat{\mathrm{Y}}=-71,1470+10,4999 \mathrm{X}-0,287131 \mathrm{X}^{2}\left(\mathrm{R}^{2}=0,97\right)$} \\
\hline $\begin{array}{l}\text { Eficiência da } \\
\text { utilização do } \\
\text { nitrogênio }\end{array}$ & \multicolumn{4}{|c|}{ Efeito quadrático $(\mathrm{P}<0,05) \hat{\mathrm{Y}}=-37,9177+13,7686 \mathrm{X}-0,448983 \mathrm{X}^{2}\left(\mathrm{R}^{2}=0,99\right)$} \\
\hline
\end{tabular}


À medida que os teores de PB da dieta foram reduzidos, a quantidade de nitrogênio consumido e excretado (Fig. 4 e 5) diminuiu de forma linear. $\mathrm{O}$ nitrogênio retido (NR) e a eficiência de utilização do nitrogênio (EUN) apresentaram efeito quadrático sobre a diminuição do teor de PB segundo as equações: $Y=$ 711470+10,4999X-0,287131X $\mathrm{X}^{2}$ (Fig. 6) e $Y=-$ $37,9177+13,7686 X-0,448983 X^{2}$ (Fig. 7). Aves alimentadas com teores de 18,3 e $15,3 \%$ de PB na dieta apresentaram, respectivamente, maior retenção e maior eficiência de utilização do nitrogênio. A menor eficiência das dietas de alta proteína, provavelmente, está relacionada à grande quantidade de $\mathrm{N}$, em excesso, a ser eliminada. Ferguson et al. (1998) também verificaram redução na concentração de NH3 no ar, da umidade da cama e da excreção de $\mathrm{N}$ ao trabalharem com teores baixos de proteína na dieta. Gates (2000) encontrou concentração mais baixa de amônia $\left(\mathrm{NH}_{3}\right)$ na cama de frangos alimentados com dietas reduzidas em PB e suplementadas com aminoácidos essenciais.

Faria Filho et al. (2005) observaram diminuição gradual da excreção de nitrogênio à medida que se reduziam o teor de proteína da dieta. Segundo os autores, a redução de 21 para 20 e para 18\% de PB na dieta resultou em redução de excreção de $\mathrm{N}$ em 11,6 e $21,7 \%$, respectivamente. No presente trabalho, quando se reduziu a PB na dieta de 21 para 19\%, houve redução da eliminação de nitrogênio de 26,3\%, e de 21 para 17 e $15 \%$ foram, respectivamente, de 39,5 e 49,6\%. Aletor et al. (2000) relataram maior eficiência de utilização e redução de $41 \%$ na eliminação de nitrogênio de uma dieta de 22,5\% de PB para outra com 15,3\%. Resultados semelhantes também foram observados por Blair et al. (1999), Silva (2004), Corzo et al. (2005) e Faria Filho et al. (2006), que encontraram menor excreção de nitrogênio e maior eficiência de retenção quando trabalharam com dietas com reduzido teor proteico e suplementadas com fitase.

Os resultados deste trabalho sugerem uma importante redução na eliminação de nitrogênio e também aumento considerável na eficiência de utilização do nitrogênio quando se utilizaram dietas de menor teor proteico. Isso pode resultar em uma importante ferramenta para diminuir o poder poluente de dejetos da produção animal.

Os valores de EMA e EMAn das dietas encontram-se na Tab. 4. Não houve efeito do teor de PB sobre os valores de EMA e EMAn.

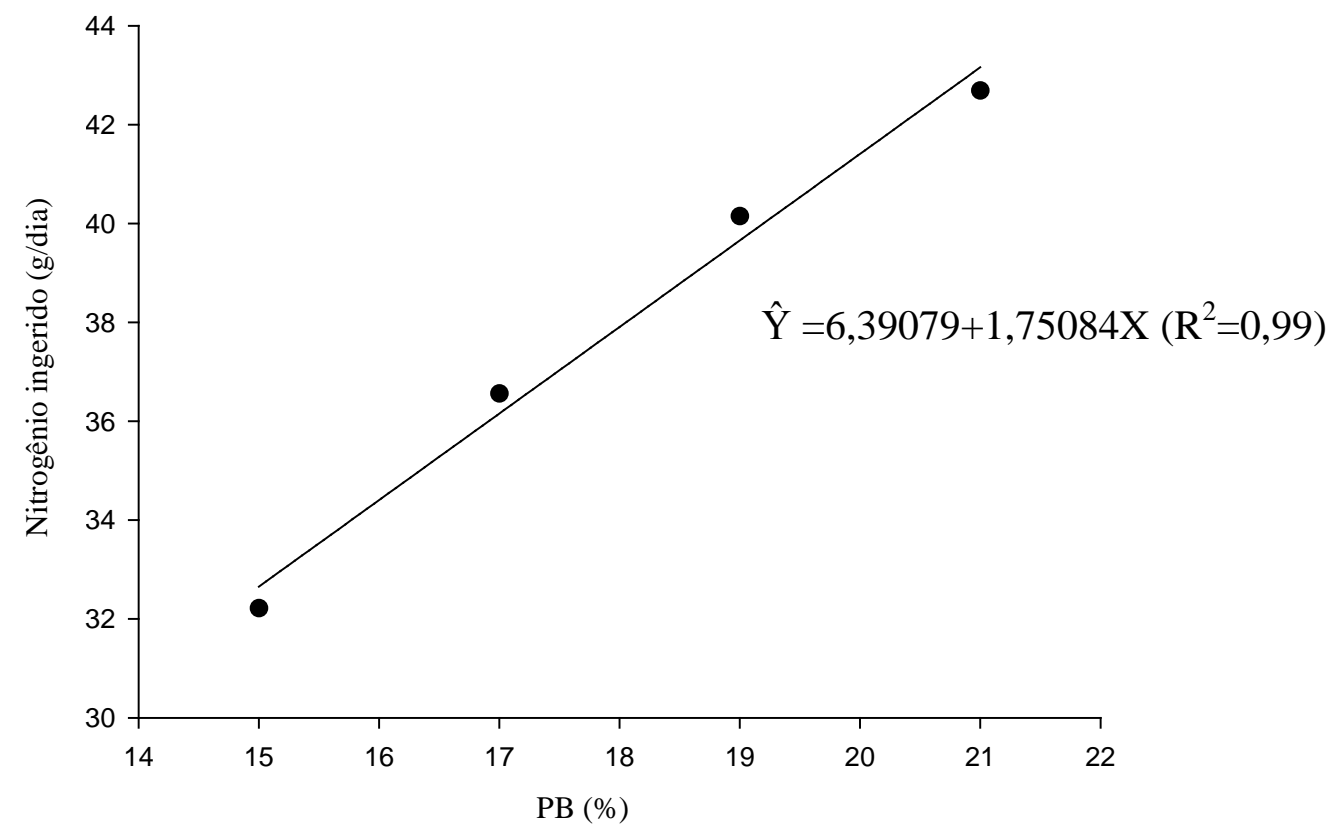

Figura 4. Regressão do nitrogênio ingerido (g/dia para 10 aves) por frangos de corte em relação ao teor de proteína bruta $(\mathrm{PB})$ da dieta. 


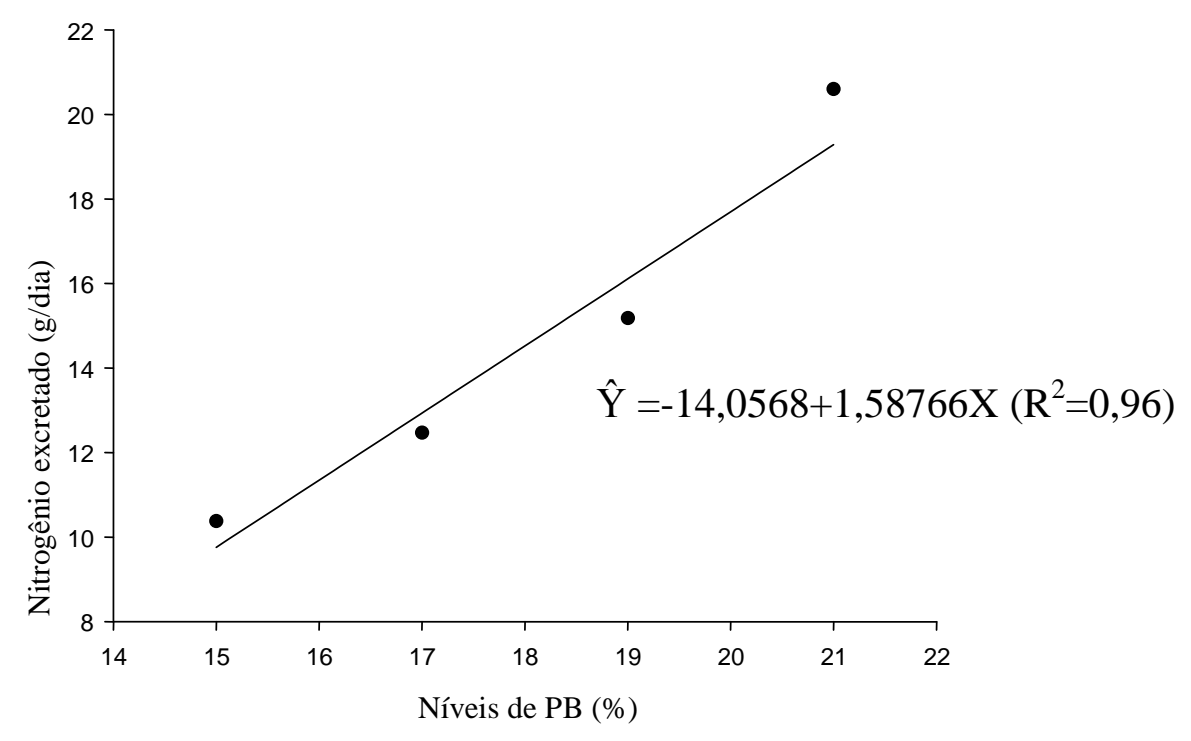

PB (\%)

Figura 5. Regressão da excreção nitrogenada (g/dia para 10 aves) de frangos de corte em relação ao teor de proteína bruta (PB) das dietas.

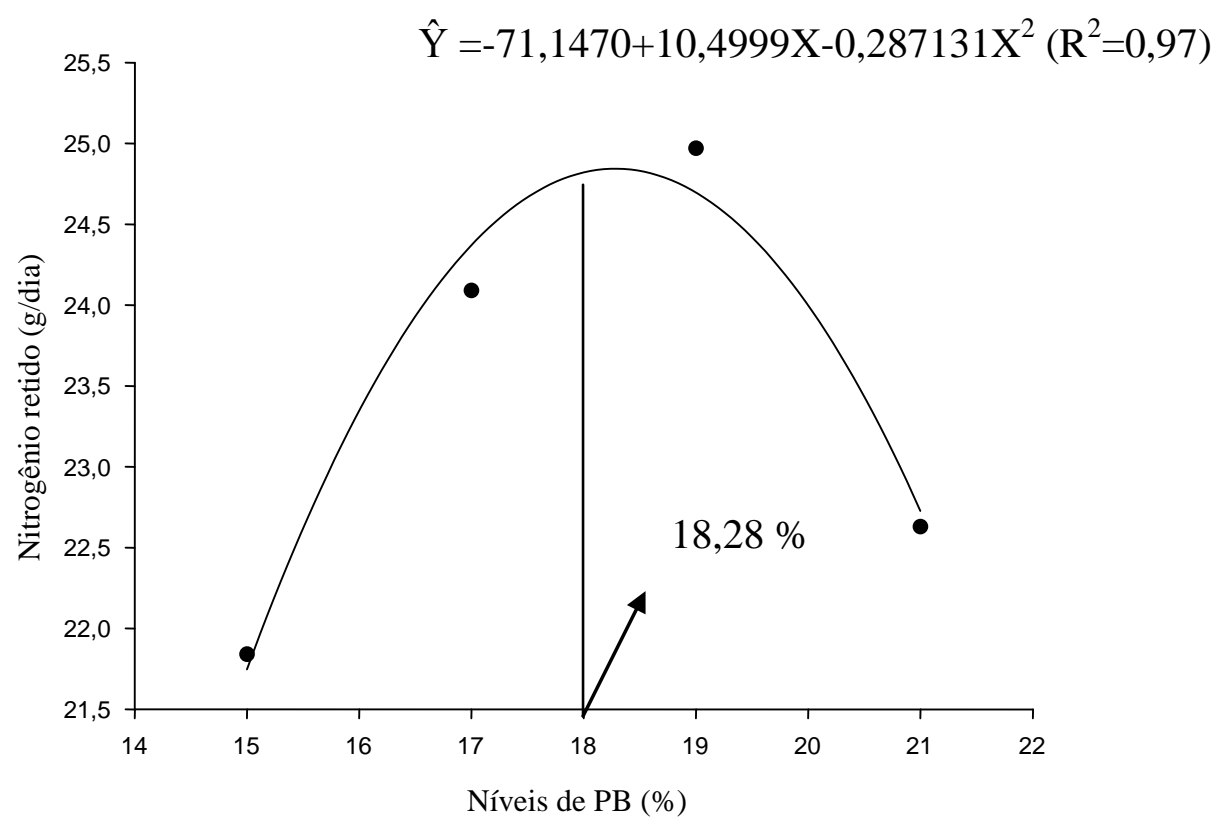

$\mathrm{PB}(\%)$

Figura 6. Regressão do nitrogênio retido (g/dia para 10 aves) em relação ao teor de proteína bruta (PB) da dieta. 


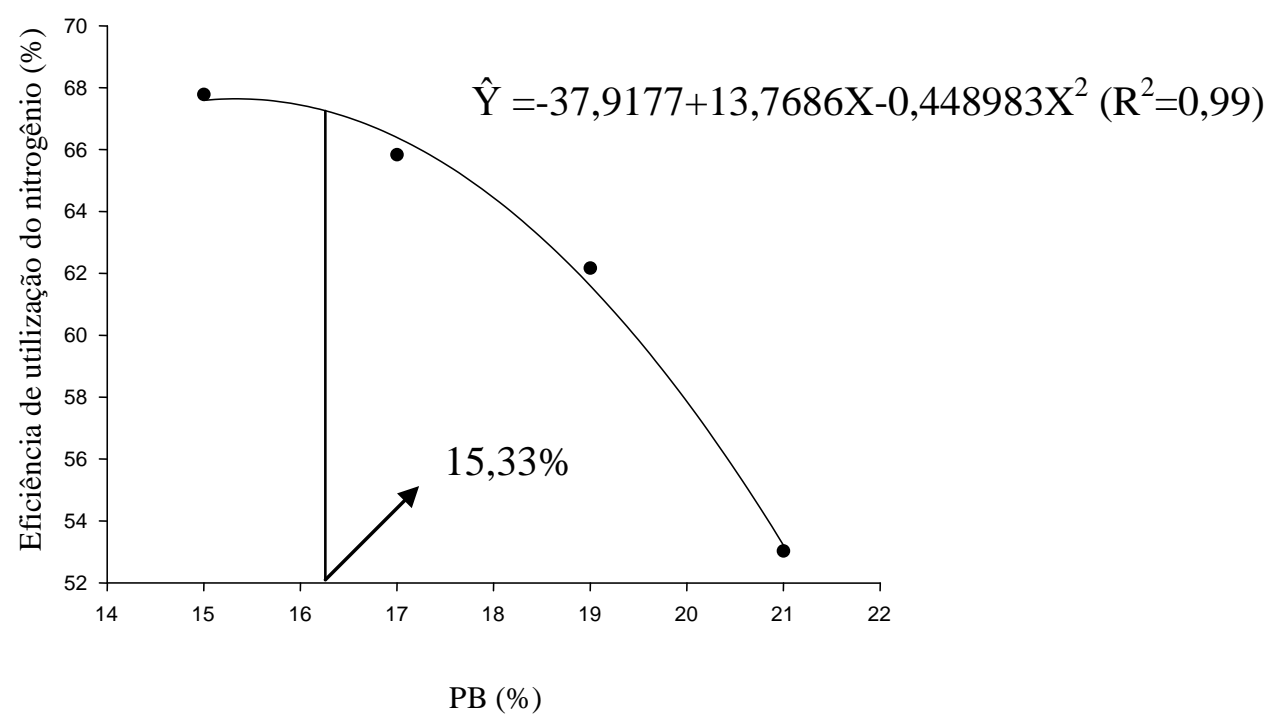

Figura 7. Regressão da eficiência de utilização do nitrogênio em relação ao teor de proteína bruta (PB) da dieta.

Tabela 4. Valores de energia metabolizável aparente (EMA) e energia metabolizável aparente corrigida para balanço de nitrogênio na matéria seca

\begin{tabular}{ccc}
\hline $\begin{array}{c}\text { Teor de } \\
\text { proteína bruta (\%) }\end{array}$ & EMA (kcal/kg) & EMAn(kcal/kg) \\
\hline 21 & 3398,49 & 3252,01 \\
19 & 3429,26 & 3273,91 \\
17 & 3385,70 & 3238,51 \\
15 & 3363,53 & 3229,82 \\
\hline CV & 1,46 & 1,37 \\
\hline Significância & ns & ns
\end{tabular}

\section{REFERÊNCIAS BIBLIOGRÁFICAS}

ALETOR, V.A.; HAMID, I.I.; NIEB, E. et al. Low-protein amino acid-supplemented diets in broiler chickens: effects on performance, carcass characteristics, whole-body composition and efficiencies of nutrient utilisation. J. Sci. Food Agric., v.80, p.547-554, 2000.

BARETTA NETTO, C. Dietas de proteína reduzida $e$ de diferentes digestibilidades suplementadas com aminoácidos industriais para frangos de corte. 2003. Dissertação (Mestrado em Zootecnia) - Universidade Federal do Rio Grande do Sul, Porto Alegre, RS.

BLAIR, R.; JACOB, J.P.; IBRAHIM, S. et al. A quantitative assessment of reduced protein diets and supplements to improve nitrogen utilization. J. Appl. Poult. Res., v.8, p.25-47, 1999.
CORZO, A.; FRITTS, C.A.; KIDD, M.T. et al. Response of broiler chicks to essential and nonessential amino acid supplementation of low crude protein diets. Anim. Feed Sci. Technol., v.118, p.319-327, 2005.

FARIA FILHO, D.E.; ROSA, P.S.; FIGUEIREDO, D.F. et al. Dietas de baixa proteína no desempenho de frangos criados em diferentes temperaturas. Pesqui. Agropecu. Bras., v.41, p.101-106, 2006.

FARIA FILHO, D.E.; ROSA, P.S.; VIEIRA, B.S. et al. Protein levels and environmental temperature effects on carcass characteristics, performance, and nitrogen excretion of broiler chickens from 7 to 21 days of age. Rev. Bras. Cienc. Avic., v.7, p. 247-253, 2005 
FERGUSON, N.S.; GATES, R.S.; TARABA, J.L. et al. The effect of dietary protein and phosphorus on ammonia concentration and litter composition in broilers. Poult. Sci., v.77, p.10851093, 1998.

GATES, R.S. Poultry diet manipulation to reduce output of pollutants to environment. In: SIMPÓSIO SOBRE RESÍDUOS DA PRODUÇÃO AVÍCOLA, 2000, Concórdia. Anais... CONCORDIA: EMBRAPA, 2000. p.6274.

KERR B.J.; KIDD, M.T. Amino acid supplementation of low - protein broiler diets 2 . Formulation on an ideal amino acid basis. $J$. Appl. Poult. Res., v.8, p.310-320, 1999.

NAMROUD, N.F.; SHIVAZAD, M.; ZAGHARI, M. Effects of fortifying low crude protein diet with crystalline amino acids on performance, blood ammonia level, and excreta characteristics of broiler chicks. Poult. Sci., v.87, p.2250-2258, 2008.

NOBLET, J.; HENRY, Y.; DUBOIS, S. Effect of protein and lysine levels in the diet on body gain composition and energy utilization in growing pigs. J. Anim. Sci., v.65, p.717-726. 1987.

OFFICIAL methods of analysis of the Association of Official Analytical Chemists. 16.ed. Washington, DC: AOAC, 1995.

REEDS, P.J.; FULLER, M.F.; CADENHEAD, A. et al. Effect os changes in the intakes of protein and non-protein energy on whole-body protein turnover in growing pigs. Br. J. Nutr., v.45, p.539-546, 1981.

ROCHA, P.T.; STRINGHINI, J.H.; ANDRADE, M.A. et al. Desempenho de frangos de corte alimentados com rações pré-iniciais contendo diferentes níveis de proteína bruta e energia metabolizável. Rev. Bras. Zootec., v.32, p.162170, 2003.
RODRIGUES, P.B.; BRITO, J.A.G.; SILVA, E.L. et al. Manejo da dieta para reduzir o impacto ambiental da excreção de nutrientes na avicultura. In: SEMINÁRIO DE AVES E SUÍNOS, 7., 2007, Belo Horizonte. Anais... Belo Horizonte: AVISUI Regiões, 2007.

ROSTAGNO, H.S. Tabelas brasileiras para aves e suínos: composição de alimentos e exigências nutricionais. Viçosa, MG: UFV, 2005. 186p.

ROSTAGNO, H.S.; VARGAS Jr., J.G.; ALBINO, L.F.T. et al. Níveis de proteína e de aminoácidos em dietas de pinto de corte. In: CONFERÊNCIA APINCO DE CIÊNCIA E TECNOLOGIA AVÍCOLAS, 2002, Campinas. Anais... Campinas: Associação Brasileira de Produtores de Pinto de Corte, 2002p.

ROTH, F.X.; GOTTERBARM, G.G.; WINDISCH, W. et al. Influence of dietary level of dispensable amino acids on nitrogen balance and whole-body protein turnover in growing pigs. J. Anim. Physiol. Anim. Nutr. v.81, p.232238, 1999.

SILVA, Y.L. Redução dos níveis de proteína e fósforo em rações com fitase para frangos de corte: desempenho, digestibilidade e excreção de nutrientes. 2004. 201f. Tese (Doutorado em Zootecnia) - Universidade Federal de Lavras, Lavras - MG, 2004.

SILVA, Y,L.; RODRIGUES, P.B.; FREITAS, R.T.F. et al. Redução de proteína e fósforo em rações com fitase para frangos de corte no período de 1 a 21 dias de idade. Desempenho e teores de minerais na cama. Rev. Bras. Zootec., v.35, p.840-848, 2006.

SISTEMA para Análises Estatísticas, Versão 9.1. Viçosa, MG: UFV, 2007.

VAN MILGEN, J.; NOBLET, J.; DUBOIS, S. Energetic efficiency of starch, protein and lipid utilization in growing pigs. J. Nutr. v.131, p.1309-1319, 2001. 